\title{
Correction to: A Multi-stakeholder Approach to Energy Transition Policy Formation in Jordan
}

Mats Danielson, Love Ekenberg, and Nadejda Komendantova

\author{
Correction to: \\ Chapter "A Multi-stakeholder Approach to Energy \\ Transition Policy Formation in Jordan" \\ in: Y. Chen et al. (Eds.): Group Decision and Negotiation \\ in an Uncertain World, LNBIP 315, \\ https://doi.org/10.1007/978-3-319-92874-6_15
}

The original version of this chapter contained an error in the third author's name. The spelling of Nadejda Komendantova's name was incorrect in the header of the paper. The author's name has been corrected.

The updated online version of this chapter can be found at https://doi.org/10.1007/978-3-319-92874-6_15 